\title{
A Modified Hypothermic Circulatory Arrest Technique Improves Early and Near-Midterm Results in Patients with Acute Type A Aortic Dissection
}

\author{
Huadong Li, MD,${ }^{1}$ Hong Yu, MD,${ }^{2}$ Nianguo Dong, $\mathrm{MD},{ }^{1}$ Long $\mathrm{Wu}, \mathrm{MD}^{1}$ \\ ${ }^{1}$ Department of Cardiovascular Surgery, Union Hospital, Tongii Medical College, Huazhong University of Science and Technology, \\ Wuhan 430022, China; ${ }^{2}$ Department of Otorhinolaryngology, Union Hospital, Tongii Medical College, Huazhong University of Science \\ and Technology, Wuhan 430022, China
}

\section{ABSTRACT}

Background: The hypothermic circulatory arrest (HCA) is an indispensable step in the surgical treatment of an acute type A aortic dissection (ATAAD), which could greatly affect the postoperative outcome. We modified the HCA technique and validated the feasibility and superiority of the new approach relative to the conventional method.

Methods and results: Eighty-eight patients with ATAAD were enrolled in this study between May 2016 and April 2018. Of those, 36 patients in the Conventional treatment group had circulatory arrest at $25^{\circ} \mathrm{C}$ for about $16-28$ minutes, while 52 patients in the Modification group underwent a circulatory arrest at $28^{\circ} \mathrm{C}$ for only $1-3$ minutes. The preoperative clinical data and postoperative clinical outcomes were compared between the two groups. No intraoperative mortality occurred in any of the cases. No significant differences were observed in the aortic cross-clamp times during the cardiopulmonary bypass $(\mathrm{CPB})$ between the two groups. In the Modification group, several indicators, such as mechanical ventilation time, postoperative 48-h drainage volume, blood transfusion volume, the ICU-stay time and postoperative hospital stay, were reduced significantly as compared with those in the Conventional group. Whereas three postoperative deaths in the hospital occurred in the Conventional treatment group, all the patients in the Modification group were cured. There is no difference in the incidence of postoperative complications between the two groups. The patients had a $100 \%$ follow up with a mean of $17 \pm 6$ months.

Conclusions: A moderate hypothermia with a short circulatory arrest is a safe and effective HCA approach that provides satisfactory early and near-midterm results in the patients who received ATAAD treatment.

\section{INTRODUCTION}

Prompt surgery is the preferred treatment for acute type A aortic dissection (ATAAD) to prevent life-threatening complications. This surgery is an extremely complex procedure,

Received April 9, 2021; accepted May 2, 2021.

Correspondence: Long Wu, 1277 Fiefang Avenue, Fianghan District, Wuban City, Hubei Province, 430022, China (e-mail:wulong@hust.edu.cn). and a variety of operative techniques are needed to ensure the optimal outcome and minimize postoperative complications and death. In recent years, advancements in surgical techniques and circulation management strategies significantly have improved the survival of ATAAD [Nienaber 2015; Hawkins 2017; Evangelista 2018; Uchida 2018; Geirsson 2019; Itagaki 2020].

Total arch replacement (TAR) and stented elephant trunk implantation (SETI) are widely used techniques in the surgical treatment of ATAAD. Hypothermic circulatory arrest (HCA) is an indispensable step in this operation and substantially affects mortality and postoperative complications [Khaladj 2008; Haldenwang 2012; Lawton 2015; Hameed 2019]. In the regular TAR and SETI, the HCA time usually is around 20-30 minutes [Sun 2004]. The length of HCA is correlated with postoperative complications, such as temporary neurologic dysfunction (TND), coagulopathic bleeding, and organ dysfunction [Svensson 1993; Hagl 2001]. Continual efforts are being made to improve the circulatory strategy for organ protection [Leshnower 2014; Keeling 2017; Zierer 2012]. By using CRONUS, a new intraoperative stent product, we have developed a new aortic arch cross-clamp technique that reduced the circulatory arrest time from the conventional duration of 16-28 minutes to 1-3 minutes in our hospital.

In the past, deep HCA was the primary strategy for tissue preservation in aortic arch surgery because it could suppress cellular metabolism during the circulatory arrest and could allow safe recovery of organ function [Damberg 2017]. But its primary disadvantage is the prolonged bypass times required for cooling and rewarming, which could lead to high rates of TND, stroke, and even mortality [Kouchoukos 2017; Cooper 2000]. Therefore, in recent years, more cardiac centers utilize a moderate $\mathrm{HCA}\left(24-28^{\circ} \mathrm{C}\right)$ in combination with anterograde cerebral perfusion (ACP) in the aortic arch surgery to shorten the cooling and rewarming time and reduce the complication. It is hard to determine the ideal temperature at which to initiate circulatory arrest, due to the numerous other variables involved in aortic surgery. Moreover, it also is difficult to elucidate the contribution of temperature to variabilities in outcomes. However, it is known the higher HCA temperature and longer HCA time, the less protective effect on organs during HCA. We modified surgical technique and reduced HCA time to only 1-3 minutes with body temperature at $28^{\circ} \mathrm{C}$, which is a maximum temperature in moderate HCA. Although some studies have reported that moderate 
Table 1. Preoperative clinical data and procedures

\begin{tabular}{lccc}
\hline Variable & $\begin{array}{c}\text { Convention } \\
\text { Group }(\mathrm{N}=36)\end{array}$ & $\begin{array}{c}\text { Modified Group } \\
(\mathrm{N}=52)\end{array}$ & $P$ \\
\hline Male sex & $28(77.78)$ & $42(80.77)$ & .785 \\
Age, years & $56(48-64)$ & $54(47-63)$ & .931 \\
BMl, kg/m², mean (SD) & $24.02(4.67)$ & $23.88(5.31)$ & .824 \\
Hypertension & $27(75)$ & $36(69.2)$ & .796 \\
History of smoking & $19(52.8)$ & $22(42.3)$ & .461 \\
Marfan syndrome & $3(8.3)$ & $6(11.5)$ & .765 \\
Previous cardiac surgery & $3(8.3)$ & $1(1.9)$ & .582 \\
Ascending aorta replacement & $22(61.1)$ & $27(51.9)$ & .714 \\
+ TAR + SETI & & $11(21.2)$ & .693 \\
Sinus replacement + TAR + & $6(16.7)$ & $8(15.4)$ & .537 \\
SETI & $8(22.2)$ & $6(11.5)$ & .032 \\
Bentall + TAR + SETI & 0 & $1(1.9)$ & .282 \\
David + TAR + SETI & $3(8.3)$ & & \\
Concomitant CABG & & & \\
\hline
\end{tabular}

BMI, body mass index; CABG, coronary artery bypass graft surgery; TAR, total arch replacement; SETI, stented elephant trunk implantation. Note: Data presented as median (interquartile range), or $\mathrm{n}(\%)$ unless otherwise indicated.

HCA $\left(29-34^{\circ} \mathrm{C}\right)$ could safely be applied to aortic arch surgery [Zierer 2012; Leshnower 2012; Hata 2013; Urbanski 2020], it still has not been widely accepted in clinical.

Our new modified circulatory arrest strategy can significantly reduce mechanical ventilation time, blood transfusion volume, postoperative hospital-stay time, the ICU-stay time, and perioperative mortality. In this report, we summarized the early and near-midterm results of using this modified technique in patients with ATAAD.

\section{MATERIAL AND METHODS}

After obtaining the ethical approval from the Wuhan Union Hospital, we retrospectively analyzed the clinical data from 88 patients with ATAAD. These patients admitted into our department between May 2016 and April 2018. The patients were divided into two groups: the Conventional group $(\mathrm{N}=36)$ which had $16-28$ minutes of circulatory arrest at $25^{\circ} \mathrm{C}$ and the Modification group $(\mathrm{N}=52)$ which had short circulatory arrest duration of $1-3$ minutes at $28^{\circ} \mathrm{C}$. Bilateral $\mathrm{ACP}$ was performed in both groups. The detailed clinical data are presented in Table 1.

Operative technique - the Conventional group: After induction of general anesthesia, the right axillary artery was cannulated for cardiopulmonary bypass (CPB) and $\mathrm{ACP}$, and standard median sternotomy was performed. Then $\mathrm{CPB}$ was carried out through the right axillary artery and right atrium, while the cooling process was initiated. When the patient was cooled
Table 2. Perioperative data

\begin{tabular}{lccc}
\hline Variable & $\begin{array}{c}\text { Convention } \\
\text { Group }(\mathrm{N}=36)\end{array}$ & $\begin{array}{c}\text { Modified Group } \\
(\mathrm{N}=52)\end{array}$ & $P$ \\
\hline HCA temperature, ${ }^{\circ} \mathrm{C}$ & 25 & 28 & \\
$\begin{array}{l}\text { CPB time, min } \\
\text { Aortic cross-clamp time, min }\end{array}$ & $103(86-130)$ & $114(79-145)$ & .372 \\
$\begin{array}{l}\text { Circulatory arrest time, min } \\
\text { Auxiliary time, min }\end{array}$ & $20(16-28)$ & $2(1-3)$ & $<.001$ \\
$\begin{array}{l}\text { Postoperative awake time, } \\
\text { hours }\end{array}$ & $41(71-156)$ & $83(62-115)$ & .021 \\
$\begin{array}{l}\text { Mechanical ventilation time, } \\
\text { hour }\end{array}$ & $59(46-50)$ & $30(21-38)$ & .043 \\
$\begin{array}{l}\text { Postoperative 48h drainage } \\
\text { volume, ml }\end{array}$ & $817(632-1054)$ & $584(496-642)$ & .002 \\
$\begin{array}{l}\text { Blood transfusion volume, } \mathrm{ml} \\
\text { ICU LOS, day }\end{array}$ & $1103(890-1325)$ & $869(708-930)$ & .011 \\
$\begin{array}{l}\text { Postoperative hospital LOS, } \\
\text { day }\end{array}$ & $7(5-9)$ & $5(4-7)$ & .342 \\
\hline
\end{tabular}

HCA, hypothermic circulatory arrest; CPB, cardiopulmonary bypass; ICU, intensive care unit; LOS, length of stay. Note: Data presented as median (interquartile range).

down to $33^{\circ} \mathrm{C}$ or the heart suffered from a ventricular fibrillation, the ascending aorta was clamped. At this time, the surgical procedures at the aortic root were carried out. Then, the patient was continuously cooled down to about $25^{\circ} \mathrm{C}$ at which circulatory arrest would be performed. The bilateral ACP was initiated through the left common carotid artery, during circulatory arrest. Meanwhile, the left subclavian, left common carotid and innominate arteries were clamped. The stented elephant trunk was inserted into the true lumen of the descending aorta, which was anastomosed to the distal end of the four-branched graft. As required, air was removed from the descending aorta after anastomosis. Blood perfusion of the lower body was initiated by the infusion limb of the four-branched graft. The left subclavian artery was anastomosed to one limb of the vascular graft. As a result, $\mathrm{CPB}$ gradually resumed to normal flow, and the rewarming started. The left common carotid artery was anastomosed end-to-end with the innominate artery. Anastomosis of the proximal end was carried out during the rewarming step. When the lung was reventilated, the ascending aorta was reopened to resume the cardiac perfusion.

When the patient was cooled down to less than $28^{\circ} \mathrm{C}$, a $\mathrm{PH}$ steady-state blood gas management was used, while an alpha steady-state blood gas management was applied when the temperature was higher than $28^{\circ} \mathrm{C}$. The whole process of cooling and rewarming was carried out at a slow and uniform rate, in a step-by-step process. After the operation, CPB was stopped when the blood gas result was satisfactory.

Operative technique - the Modification group: After the induction of general anesthesia, the femoral artery was 


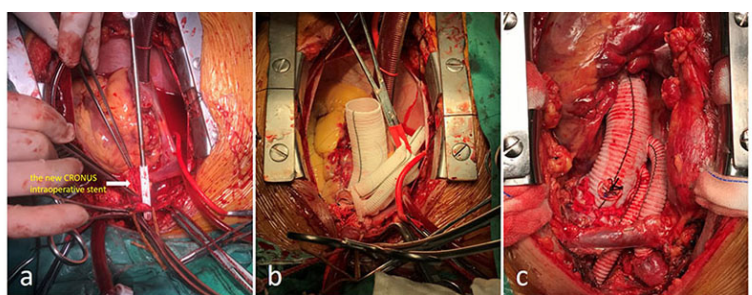

The modified hypothermia-based circulatory arrest technique in the aortic arch replacement. (A) After inserting the stented elephant trunk into the true lumen of the descending aorta, the suturable artificial blood vessel (about $5 \mathrm{~cm}$ long) of the new CRONUS stent was pulled out and clamped near the level of the left common carotid artery. (B) After resuming the circulation, the four-branched vascular graft was sutured with the suturable artificial blood vessel of the stent. (C) The four-branched vascular graft was connected to the aortic root and the three branches of the aortic arch were replaced.

cannulated and $\mathrm{CPB}$ was instituted through the right axillary artery and the right atrium. There were no differences in the pre-parallel stage and myocardial protection compared with the Conventional group. When the patients were cooled down to $28^{\circ} \mathrm{C}$, a bilateral ACP through the left common carotid artery (DLP artery cannula 16Fr) was performed, and the circulation was arrested. During this time, an intraoperative stent (CRONUS) was implanted into the descending aorta, the suturable artificial blood vessel (about $5 \mathrm{~cm}$ ) was pulled out and clamped near the left common carotid artery, and the femoral artery perfusion was started (Figure, A). The circulatory arrest duration was only about 1-3 minutes. After resuming the circulation, the four-branched vascular graft and the suturable artificial blood vessel of the stent were sutured (Figure, B). The four-branched graft was used for blood supply with the cross-clamp of the femoral artery. After the aortic root was anastomosed with the vascular graft for the cardiac reperfusion, the other limbs of the four-branched graft were reconstructed one by one (Figure, C). The rewarming process, timing, and medications in the Modification group were the same as in the Conventional group. In the Modification group, Alpha steady state blood gas management was used.

Postoperative evaluation and follow up: All patients were transferred to the intensive care unit (ICU) for post-surgical monitoring. Before discharge, the patients underwent medical examinations to assess recovery, including routine clinical examination, electrocardiography, chest radiography, and transthoracic echocardiography. After discharge, the patients received routine echocardiography at three, six, and 12 months post-surgery and then annually thereafter. Aortic computed tomography angiography (CTA) examination was performed three months post-surgery and then annually to evaluate the vascular graft, prosthetic stents, and closure of the distal false lumen.

Statistical analysis: The continuous variables with normal distributions were expressed as mean \pm standard deviation (SD) and were compared by the independent t-test. The continuous variables with non-normal distributions were
Table 3. Postoperative follow-up data

\begin{tabular}{lccc}
\hline Complication & $\begin{array}{c}\text { Convention } \\
\text { Group }(\mathrm{N}=36)\end{array}$ & $\begin{array}{c}\text { Modified Group } \\
(\mathrm{N}=52)\end{array}$ & $P$ \\
\hline $\begin{array}{l}\text { Postoperative death in } \\
\text { hospital }\end{array}$ & $3(8.33)$ & 0 & .041 \\
Postoperative coma & $1(2.78)$ & 0 & .538 \\
Postoperative paraplegia & $1(2.78)$ & 0 & .538 \\
Postoperative CRRT & $2(5.56)$ & $2(3.85)$ & .645 \\
Postoperative tracheotomy & $5(13.89)$ & $3(5.77)$ & .563 \\
Postoperative multiorgan & $3(8.33)$ & 0 & .041 \\
failure & $1(2.78)$ & $2(3.85)$ & .863 \\
Postoperative thoracotomy & 0 & $1(1.92)$ & .642 \\
Delayed chest closure & $4(11.11)$ & $5(9.62)$ & .732 \\
TND & $1(2.78)$ & $2(3.85)$ & .913 \\
PND & 0 & 0 & 1.000 \\
Reoperation after discharge & 0 & 0 & 1.000 \\
Death after discharge & &
\end{tabular}

CRRT, continuous renal replacement therapy; PND, permanent neurological dysfunction; TND, temporary neurological dysfunction. Note: Data presented as $\mathrm{n}(\%)$.

expressed as the median and interquartile range and were compared by a Mann-Whitney U test. All statistical analyses were performed with SPSS 22.0 (SPSS Inc., Chicago, IL, USA). The confidence interval of all tests was $95 \%$, and differences with $P$-values less than 0.05 were considered statistically significant.

\section{RESULTS}

The preoperative clinical characteristics of the 88 patients with AATAD are listed in Table 1. Most of patients had dissection in the ascending aorta: $61.1 \%$ in the Conventional group and $51.9 \%$ in the Modification group. All patients underwent TAR and SETI with bilateral ACP. No intraoperative deaths occurred in any group. As shown in Table 2, the patients in the Modification group underwent a short circulatory arrest (1-3 minutes versus $16-28$ minutes, $P<.001)$ at a higher temperature $\left(28^{\circ} \mathrm{C}\right.$ versus $\left.25^{\circ} \mathrm{C}\right)$. There was no significant difference in the CPB time or the aortic cross-clamp time between the two groups. But the mechanical ventilation time, postoperative anesthesia recovery time, ICU stay time, and postoperative hospital stay time were much shorter in the Modification group of patients ( $P=.038, .043, .042$, and .041 , respectively). Furthermore, the blood transfusion volume and the postoperative $48 \mathrm{~h}$ drainage were greatly reduced in patients of the Modification group ( $P=.011$ and .002 , respectively).

As shown in Table 3, there were three reported postoperative deaths, one case of coma, and one case of paraplegia in the Conventional group. In addition, there were five cases of 
tracheotomy, three cases of multiorgan failure, and one case of secondary thoracotomy. There were two cases with postoperative continuous renal replacement therapy (CRRT): One had preoperative renal dysfunction, and the other had significantly elevated myoglobin, due to the lower limb ischemia.

On the contrary, all patients from the Modification group were discharged without perioperative death, coma, or paraplegia. However, there were three cases of tracheotomy, two cases of secondary thoracotomy, and one case of delayed chest closure. In addition, there were two cases of CRRT (one due to preoperative renal dysfunction, and the other due to bilateral lower limb ischemia).

After discharge, all patients were successfully followed up at mean $17 \pm 6$ months (range, 12-24 months) with no death or reoperation. However, there were four cases of transient neurological dysfunction (TND) and one case of permanent neurological dysfunction (PND) in the Conventional group, while there were five cases of TND and two cases of PND in the Modification group. In the Modification group, two TND cases had a cardiac arrest during the chest closure, and an emergency CPB was performed through the femoral artery. Another TND case was associated with hypotension from an intraoperative hemorrhage. One PND case had a softening lesion in the basal ganglia region revealed by a preoperative brain CT. The other PND case had no blood return after cutting off the left common carotid artery, and a bilateral ACP immediately was performed. This patient's pupil size was changing during the operation, and postoperative recovery was delayed. This patient underwent tracheotomy after surgery and brain CT showed a cerebral infarction.

\section{DISCUSSION}

Acute type A aortic dissection, as a life-threatening disease with high mortality, requires prompt diagnosis and treatment. There are many surgical techniques and perfusion strategies, ranging from simple interposition graft to FAR with SETI and valve-sparing root reconstruction. For patients with ATAAD involving total arch replacement, the most common surgical treatment is FAR and SETI under moderate HCA and ACP, which can result in a satisfactory outcome [Sun 2011; El-Sayed 2017; Wang 2019]. Surgical treatment of FAR and SETI under HCA and ACP is a challenging procedure that is associated with high rates of mortality and serious complications, such as hemorrhage, cerebral ischemia, cardiogenic shock, and distal malperfusion. To reduce the high operative mortality, cardiovascular surgeons make efforts in improving surgical methods and circulatory management strategies with the development of surgical instruments and stent grafts.

Owing to the longer suturable artificial blood vessel size (about $5 \mathrm{~cm}$ ) of the new CRONUS stent, a new aortic arch cross-clamp technology is developed that reduces the circulatory arrest time to 1-3 minutes. This could greatly reduce the side effects associated with HCA. The longer suturable artificial blood vessel could be clamped after releasing the stent so that the distal organs could be reperfused through the femoral artery. Following the restoration of perfusion, the stent vessel and the four-branched vascular graft were anastomosed. In the Conventional group, such anastomosis was performed during the circulatory arrest. Accurate modeling/design of the appropriate intraoperative stent size and its release position are critical: Too deep or too shallow a position could greatly affect the arch occlusion. The arch should be cross-clamped as close as possible to the distal end, leaving enough space for the proximal and ascending aortic anastomoses. Based on the perioperative, early, and near-midterm outcomes, we found no complications or deaths related to the new technique. Therefore, the new technique is safe and effective to use.

The modified procedure greatly improves the perioperative circulation. Owing to the very short circulatory arrest time (only 1-3 minutes), it was sufficient to cool down the patients to $28^{\circ} \mathrm{C}$ during the $\mathrm{HCA}$, as there was no need in using lower temperatures. Thus, the duration of the entire operation was shortened by reducing the cooling and rewarming time. (Table 3) The temperature could not, however, stay higher than $28^{\circ} \mathrm{C}$, as it would not support the protection of the spinal cord and the brain [Linardi 2016]. Some studies have shown that there was no significant difference in the postoperative outcomes between unilateral and bilateral ACPs for patients with normal circle of Willis [Norton 2019]. However, the bilateral cerebral perfusion is favorable for patients with vascular stenosis, malformation, or right aortic arch [Küçüker 2005]. Therefore, all patients in our study were treated with bilateral ACP for brain protection.

In the Modification group, the distal organs were perfused through the femoral arteries, during a bilateral ACP, and it was converted into the four-branched vascular graft for blood supply after completing the anastomosis of the four-branched graft and the stent vessel. The whole process of $\mathrm{CPB}$ prevented the retrograde blood flow to cerebral blood vessels. The axillary arteries were utilized during the course of cooling at the beginning of CBP, while the femoral arteries were added only if the patient's body weight exceeded $100 \mathrm{~kg}$ or if the cooling occurred slowly in the lower body, which may increase the risk of emboli into the brain during reperfusion. Of five TND cases in the Modification group, there were four cases of retrograde infusion through the femoral artery during cooling. In the majority of cases, the femoral artery perfusion was only used during the anastomosis of the fourbranched graft and the stent vessel. The cerebral embolism, caused by thrombosis of the false cavity, was rare.

This study is limited by its retrospective design and small sample size. Thus, a prospective randomized controlled clinical trial with a large patient cohort for long-term follow up will be needed. In summary, this study showed that a moderate hypothermia with a short circulatory arrest is a safe and effective HCA approach that provides satisfactory early and near-midterm results in the ATAAD treatment.

\section{ACKNOWLEDGEMENT}

We are grateful to Prof. Xionggang Jiang and Kailun Zhang for suggestions on the improvement of surgical methods and 
circulatory strategy. This work was supported by the National Natural Science Foundation of China grant 81500301.

\section{REFERENCES}

Cooper WA, Duarte IG, Thourani VH, et al. 2000. Hypothermic circulatory arrest causes multisystem vascular endothelial dysfunction and apoptosis. Ann Thorac Surg. Mar;69(3):696-702; discussion 703.

Damberg A, Carino D, Charilaou P, et al. 2017. Favorable late survival after aortic surgery under straight deep hypothermic circulatory arrest. J Thorac Cardiovasc Surg. Dec;154(6):1831-1839.e1.

El-Sayed Ahmad A, Papadopoulos N, Risteski P, et al. 2017. The Standardized Concept of Moderate-to-Mild $\left(\geq 28^{\circ} \mathrm{C}\right)$ Systemic Hypothermia During Selective Antegrade Cerebral Perfusion for All-Comers in Aortic Arch Surgery: Single-Center Experience in 587 Consecutive Patients Over a 15-Year Period. Ann Thorac Surg. 104(1):49-55.

Evangelista A, Isselbacher EM, Bossone E, et al. 2018. Insights from the International Registry of Acute Aortic Dissection: A 20-Year Experience of Collaborative Clinical Research. Circulation. Apr 24;137(17):1846-1860.

Geirsson A, Shioda K, Olsson C, et al. 2019. Differential outcomes of open and clamp-on distal anastomosis techniques in acute type A aortic dissection. J Thorac Cardiovasc Surg. May;157(5):1750-1758.

Hagl C, Ergin MA, GallaJD, et al. 2001. Neurologic outcome after ascending aorta-aortic arch operations: effect of brain protection technique in high-risk patients. J Thorac Cardiovasc Surg. Jun;121(6):1107-21.

Haldenwang PL, Wahlers T, Himmels A, et al. 2012. Evaluation of risk factors for transient neurological dysfunction and adverse outcome after repair of acute type A aortic dissection in 122 consecutive patients. Eur J Cardiothorac Surg. 42(5): e115-e120.

Hameed I, Rahouma M, Khan FM, et al. 2019. Cerebral protection strategies in aortic arch surgery: A network meta-analysis. J Thorac Cardiovasc Surg. S0022-5223(19)30483-0.

Hata M, Akiyama K, Hata H, Sezai A, Yoshitake I, Wakui S, Shiono M. 2013. Early and midterm outcomes of quick proximal arch replacement with mild hypothermia and rapid rewarming for type A acute aortic dissection. J Thorac Cardiovasc Surg. Jul;146(1):119-23.

Hawkins RB, Mehaffey JH, Downs EA, et al. 2017. Regional practice patterns and outcomes of surgery for acute type A aortic dissection. Ann Thorac Surg. 104(4):1275-1281.

Itagaki S, Chikwe J, Sun E, et al. 2020. Impact of Cerebral Perfusion on Outcomes of Aortic Surgery: The Society of Thoracic Surgeons Adult Cardiac Surgery Database Analysis. Ann Thorac Surg. Feb;109(2):428-435.

Keeling WB, Leshnower BG, Hunting JC, et al. 2017. Hypothermia and Selective Antegrade Cerebral Perfusion Is Safe for Arch Repair in Type A Dissection. Ann Thorac Surg. Sep;104(3):767-772.

Khaladj N, Shrestha M, Meck S, et al. 2008. Hypothermic circulatory arrest with selective antegrade cerebral perfusion in ascending aortic and aortic arch surgery: a risk factor analysis for adverse outcome in 501 patients. J Thorac Cardiovasc Surg. Apr;135(4):908-14.
Kouchoukos NT. 2017. Straight deep hypothermic circulatory arrest for aortic arch surgery: Going the way of the dinosaurs? J Thorac Cardiovasc Surg. Dec;154(6):1840-1841.

Küçüker SA, Ozatik MA, Sarita A, Ta demir O. 2005. Arch repair with unilateral antegrade cerebral perfusion. Eur J Cardiothorac Surg. 27(4):638-643.

Lawton JS, Liu J, Kulshrestha K, et al. 2015. The impact of surgical strategy on survival after repair of type A aortic dissection. J Thorac Cardiovasc Surg. 150(2):294-301.e1.

Leshnower BG, Kilgo PD, Chen EP. 2014. Total arch replacement using moderate hypothermic circulatory arrest and unilateral selective antegrade cerebral perfusion. J Thorac Cardiovasc Surg. May;147(5):1488-92.

Leshnower BG, Myung RJ, Thourani VH, Halkos ME, Kilgo PD, Puskas JD, Chen EP. 2012. Hemiarch replacement at $28^{\circ} \mathrm{C}$ : an analysis of mild and moderate hypothermia in 500 patients. Ann Thorac Surg. Jun;93(6):1910-5; discussion 1915-6.

Linardi D, Faggian G, Rungatscher A. 2016. Temperature Management During Circulatory Arrest in Cardiac Surgery. Ther Hypothermia Temp Manag. Mar;6(1):9-16.

Nienaber CA, Clough RE. 2015. Management of acute aortic dissection. Lancet. Feb 28;385(9970):800-11.

Norton EL, Wu X, Kim KM, et al. 2019. Unilateral is comparable to bilateral antegrade cerebral perfusion in acute type A aortic dissection repair [published online ahead of print, 2019 Sep 5]. J Thorac Cardiovasc Surg. S0022-5223(19)31700-3.

Sun L, Qi R, Zhu J, et al. 2011. Total arch replacement combined with stented elephant trunk implantation: a new "standard" therapy for type a dissection involving repair of the aortic arch? Circulation. Mar 8;123(9):971-8.

Sun LZ, Liu ZG, Chang Q, et al. 2004. [Total arch replacement combined with stented elephant trunk implantation for Stanford type A aortic dissection]. Zhonghua Wai Ke Za Zhi. Jul 7;42(13):812-6. Chinese.

Svensson LG, Crawford ES, Hess KR, et al. 1993. Deep hypothermia with circulatory arrest. Determinants of stroke and early mortality in 656 patients. J Thorac Cardiovasc Surg. Jul;106(1):19-28; discussion 28-31.

Uchida K, Karube N, Kasama K, et al. 2018. Early reperfusion strategy improves the outcomes of surgery for type A acute aortic dissection with malperfusion. J Thorac Cardiovasc Surg. 156(2):483-489.

Urbanski PP, Thamm T, Bougioukakis P, Irimie V, Prasad P, Diegeler A, Lenos A. 2020. Efficacy of unilateral cerebral perfusion for brain protection in aortic arch surgery. J Thorac Cardiovasc Surg. Feb;159(2):365371.e1.

Wang X, Yang F, Zhu J, et al. 2019. Aortic arch surgery with hypothermic circulatory arrest and unilateral antegrade cerebral perfusion: Perioperative outcomes. J Thorac Cardiovasc Surg. Feb 14: S0022-5223(19)30362-9.

Zierer A, El-Sayed Ahmad A, Papadopoulos N, et al. 2012. Selective antegrade cerebral perfusion and mild $\left(28^{\circ} \mathrm{C}-30^{\circ} \mathrm{C}\right)$ systemic hypothermic circulatory arrest for aortic arch replacement: results from 1002 patients. J Thorac Cardiovasc Surg. 144(5):1042-1049. 